\title{
Upregulation of HIF-1 $\alpha$ protects neuroblastoma cells from hypoxia-induced apoptosis in a RhoA-dependent manner
}

\author{
CUI-PING YIN ${ }^{1}$, SHANG-HUI GUAN ${ }^{2}$, BO ZHANG $^{3}$, XUE-XIN WANG ${ }^{4}$ and SHOU-WEI YUE ${ }^{1}$
}

\author{
Departments of ${ }^{1}$ Physical Medicine and Rehabilitation and ${ }^{2}$ Radiation Oncology, Qilu Hospital of Shandong University, \\ Jinan, Shandong 250012; ${ }^{3}$ Department of Physical Medicine and Rehabilitation, Dongying People's Hospital, \\ Dongying, Shandong 257091; ${ }^{4}$ Department of Physical Medicine and Rehabilitation, \\ Yuhuangding Hospital, Yantai, Shandong 264000, P.R. China
}

Received November 13, 2014; Accepted July 29, 2015

DOI: $10.3892 / \mathrm{mmr} .2015 .4267$

\begin{abstract}
Hypoxic conditions regulate several metabolic enzymes and transcription factors that are involved in cancer, ischemia and pulmonary diseases. The Ras homolog (Rho) family, including Rho member A (RhoA), is involved in reorganization of the actin cytoskeleton, cell migration and in the regulation of apoptosis and gene transcription. The aim of the present study was to investigate the expression of hypoxia-inducible factor (HIF)- $\alpha$ and the activity of RhoA in PC12 neuroblastoma cells under hypoxic conditions. The upregulation of HIF- $\alpha$ and RhoA by hypoxia was determined using reverse transcription-quantitative polymerase chain reaction and western blot assays, cell apoptosis was analyzed using flow cytometry, and the activity of caspase 3 was examined using a western blot assay and caspase 3 activity assay kit. The PC12 cells were induced to apoptosis following exposure to hypoxia, and exhibited increased expression of HIF- $\alpha$ and increased mRNA and protein expression levels of RhoA. The overexpression of HIF- $\alpha$ attenuated the hypoxia-induced apoptosis of the PC12 cells. In addition, RhoA knockdown using small interfering RNA abrogated the antagonism of HIF-1 $\alpha$ towards hypoxia-induced apoptosis. The results of the present study confirmed the protective role of HIF-1 $\alpha$ and RhoA in hypoxia-induced PC12 cell apoptosis, and that the upregulation of HIF-1 $\alpha$ by hypoxia is RhoA-dependent.
\end{abstract}

\section{Introduction}

Accumulating evidence has demonstrated that nerve terminals are vulnerable to various stimuli, including traumatic, toxic and disease-associated neurodegenerative factors (1). As one

Correspondence to: Professor Shou-Wei Yue, Department of Physical Medicine and Rehabilitation, Qilu Hospital of Shandong University, 107 West Culture Road, Jinan, Shandong 250012, P.R. China E-mail: showeyue@163.com

Key words: hypoxia-inducible factor $\alpha$, hypoxia, apoptosis, PC12 cells, Ras homolog, member A of these pathological stimuli, ischemia/hypoxia has been extensively investigated in the central nervous system (CNS), including stroke-induced brain damage (2). However, few studies have focused on the stimulation of ischemia/hypoxia on the peripheral nervous system (PNS), although the PNS can be highly susceptible to reductions in blood supply and oxygen levels during surgical and pathological conditions $(3,4)$ and can cause neurological complications, ranging from mild functional loss to complete limb paralysis and permanent functional deficits (5). Hypoxia is considered to be the key pathological stimulus in CNS ischemia (6) and also induces functional changes at the neuromuscular junction $(7,8)$. The mechanisms underlying nerve terminal vulnerability to hypoxia-reperfusion injury in situations, including trauma, remain to be fully elucidated (9) and require further investigation. The majority of current in vivo animal models of hypoxia-reperfusion rely on the experimental application of high-pressure tourniquets, which may induce considerable mechanical stress and potential crush injury to the underlying nerves, making it difficult to conclusively distinguish the effects of ischemia-reperfusion injury from the effects of mechanical trauma (10).

During ischemia/hypoxia-induced damage to the CNS/PNS or other organs, there are two major processes, necrosis and apoptosis, leading to neural cell death. In the core ischemic area, the severe restriction of blood flow leads to necrotic cell death. However, in the peripheral ischemic area, where collateral blood flow can buffer the degree of damage, cell apoptosis predominantly develops $(11,12)$. Evidence suggests that activation of apoptotic pathways occurs in the peripheral cells of the ischemic area, in a caspase-dependent and caspase-independent manner $(13,14)$. Therefore, the apoptotic cascades during the ischemia/hypoxia-induced damage to CNS/PNS are reversible and are a major target of therapeutic interventions $(15,16)$.

A variety of transcription factors have been reported to be involved in regulating the genes responsible for the metabolic responses to hypoxia-ischemia $(17,18)$. A key component among these factors is hypoxia-inducible factor 1 (HIF-1), existing as a heterodimer which is composed of a constitutively expressed HIF-1 $\beta$ subunit and an oxygen sensitive HIF-1 $\alpha$ subunit. Following activation by hypoxia, the HIF- $1 \alpha / \mathrm{HIF}-1 \beta$ dimmer (19) binds to a conserved DNA consensus on the promoters of its target genes, known as the hypoxia-responsive 
element $(20,21)$, and induces a group of gene products that are crucial for hypoxic adaptation (22). An anti-apoptotic and a pro-apoptotic effect have been confirmed for HIF-1 and/or hypoxia in hypoxia-ischemia. Severe or prolonged hypoxia induces apoptosis, at least in part, whereas activated HIF-1 $\alpha$, along with other molecules, protects neural cells from apoptosis (23). HIF-1 $\alpha$ can prevent apoptosis by activating the phosphoinositide 3-kinase (PI3K)/Akt pathway (24) or by promoting the expression of survivin (25) in acute hypoxia, or by increasing the expression of glycolytic enzymes, p21 and erythropoietin to antagonize the effect of the hypoxia- and/or hypoglycaemia-induced expression of tumor suppressor gene p53 (26) or BNIP3 (27). However, other molecules involved in the pro- or anti-apoptotic effects of HIF-1 $\alpha$ in hypoxia-ischemia damage in the CNS/PNS require investigation.

In the present study, in order to investigate the role of HIF- $1 \alpha$ and Ras homolog gene family, member A (RhoA) in hypoxic-ischemic damage to the CNS/PNS, PC12 neuroblastoma cells were examined following hypoxia treatment. The expression levels of HIF-1 $\alpha$ and RhoA, which belongs to the Rho small GTPase family and is reported to be implicated in hypoxia adaptation were assessed. Subsequently, gain-of-function and loss-of-function strategies were adopted to manipulate the expression levels of HIF-1 $\alpha$ or RhoA in PC12 cells, and the expression of hypoxia-induced RhoA and cell apoptosis were determined again.

\section{Materials and methods}

Reagents, cell culture and treatment. The PC12 rat pheochromocytoma cell line was provided by the National Platform of Experimental Cell Resources for Sci-Tech (Beijing, China) and were cultured in F12K medium (Invitrogen Life Technologies, Carlsbad, CA, USA) containing 15\% fetal calf serum (Invitrogen Life Technologies) at $37^{\circ} \mathrm{C}$ under $5 \% \mathrm{CO}_{2}$. F12K medium supplemented with $2 \%$ fetal bovine serum was used for the cell maintenance. For hypoxia treatment, the cells at $85 \%$ confluence were placed in a hypoxia incubator infused with a gas mixture of $5 \% \mathrm{CO}_{2}$ and nitrogen to obtain a $3 \%$ oxygen concentration, at $37^{\circ} \mathrm{C}$ for $0,2,4,6,12,24$ or $48 \mathrm{~h}$. The oxygen concentration was monitored continuously (Forma 3130; Thermo Fisher Scientific, Rockford, IL, USA). To overexpress HIF- $1 \alpha$ in the PC12 cells, the wild-type HIF-1 $\alpha$ coding sequence was amplified with Pfu DNA polymerase (Promega, Madison, WI, USA) and cloned into a pcDNA3.1 (+) vector (Invitrogen life Technologies), with HindIII and BamHI (New England Biolabs, Ipswich, MA, USA) as restriction endonucleases. The HIF-1 $\alpha$-pcDNA3.1 (+) or control CAT-pcDNA3.1 (+) plasmids were then transfected, respectively, into PC12 cells using Lipofectamine 2000 (Invitrogen Life Technologies), and 25 or $50 \mathrm{nM}$ small interfering (si) RNA-RhoA or siRNA-Control (Sangon Biotech, Co., Ltd., Shanghai, China) were transfected into the cells using Lipofectamine 2000 to knockdown the expression of RhoA.

$R N A$ isolation and reverse transcription-quantitative polymerase chain reaction ( $R T-q P C R)$. Total cellular RNA was isolated from the cells using a PureLink ${ }^{\circledR}$ RNA Mini kit (Invitrogen Life Technologies), according to the manufacturer's instructions. The mRNA expression levels of HIF-1 $\alpha$ and RhoA were quantified by RT-qPCR using a Takara One Step RT-PCR kit (Takara Biotechnology, Co., Ltd., Dalian, China) and paired primers as follows: HIF-1 $\alpha$, forward 5'-aac cataacaaaaccatcca-3', and reverse 5'-tattgaagatgacatgaaag-3'; RhoA, forward 5'-gtggcagatatcgaggtgga-3' and reverse 5'-aat cttcctgcccagctgtg-3' and $\beta$-actin, forward $5^{\prime}$-tgtccaccttccagc agatgt-3' and reverse 5'-gtaacagtccgcctaga-3' (Sangon Biotech, Co., Ltd.). Equal quantities of mRNA sample $(1 \mu \mathrm{l})$ were used for quantitative analysis. The RT-qPCR was performed as follows: $65^{\circ} \mathrm{C}$ for $5 \mathrm{~min}, 42^{\circ} \mathrm{C}$ for $40 \mathrm{~min}$ and $95^{\circ} \mathrm{C}$ for $10 \mathrm{sec}$ for the reverse transcription step then $95^{\circ} \mathrm{C}$ for $5 \mathrm{sec}$ and $60^{\circ} \mathrm{C}$ for $10 \mathrm{sec}(40$ cycles) for the PCR reaction. The mRNA samples were amplified using primer/probe sets specific for the genes of interest on a Lightcycler 480 II (Roche Diagnostics, Mannheim, Germany). Relative quantification was determined using the $\Delta \Delta \mathrm{Ct}$ method (28), with tubulin as a reference gene (28).

Western blot analysis. To determine protein expression levels, $5 \times 10^{5} \mathrm{PC} 12$ cells were collected and lyzed using a cytoplasmic protein extraction kit (TP-001; ZmTech Scientific, Inc., San Jose, CA, USA) and supplemented with a protease inhibitor cocktail (Roche Diagnostics) according to the manufacturer's instructions. All protein samples were quantified using Bradford protein assay reagent (Bio-Rad Laboratories, Inc., Hercules, CA, USA) and each sample with $30 \mu \mathrm{g}(5 \mu \mathrm{l})$ was separated on a $8-12 \%$ gradient SDS-PAGE gel, followed by being transferred onto a polyvinylidene difluoride membrane and blocked in 5\% skimmed milk. Rabbit polyclonal antibodies against caspase 3 (1:1,000; cat. no. ab2302; Abcam, Cambridge, UK), Poly ADP ribose polymerase (PARP; 1:500; cat. no. ab137653; Abcam), cytochrome $c(1: 1,000$; cat. no. 4272; Cell Signaling Technology Inc., Danvers, MA, USA), HIF-1 $\alpha$ (1:1,000; cat. no. sc-10790; Santa Cruz Biotechnology, Inc., Santa Cruz, CA, USA), HIF-1 $\beta$ (1:500; cat. no. C15A11, Cell Signaling Technology Inc.), RhoA (1:1,000; cat. no. sc-179, Santa Cruz Biotechnology, Inc.), Rho-associated kinase (Rock) 1 (1:500; cat. no. sc-5560, Santa Cruz Biotechnology, Inc.), Rock 2 (1:1,000; cat. no. sc-5561, Santa Cruz Biotechnology, Inc.), RhoB (1:1,000; cat. no. sc-180, Santa Cruz Biotechnology, Inc.) and $\beta$-actin (1:500; cat. no. sc-130656, Santa Cruz Biotechnology, Inc.) were used to quantify the protein level of each molecule via an incubation at $4^{\circ} \mathrm{C}$ overnight. Goat anti-rabbit IgG conjugated to horseradish peroxidase (1:500; cat. no. 31212, Pierce Biotechnology, Inc., Rockford, IL, USA) and an enhanced chemiluminescence detection system (Super Signal West Femto; Pierce Biotechnology, Inc.) were used for detection and quantification. Prior to each inoculation, samples were washed four times with $1 \mathrm{X}$ phosphate-buffered saline with Tween-20.

Apoptosis and caspase 3 assays. The apoptosis of the PC12 cells was examined using an Annexin V-FITC Apoptosis Detection kit (Sigma-Aldrich, St. Louis, MO, USA). Briefly, $4 \times 10^{5}$ cells were stained with Annexin V-fluorescein isothiocyanate (FITC; $5 \mu 1$ Annexin V-FITC conjugate in $1 \mathrm{ml}$ suspended cells) and propidium iodide (10 $\mu$ l propidium iodide solution in $1 \mathrm{ml}$ suspended cells), and detected using a FACScan flow cytometer (Bio-Rad Laboratories, Inc.) to analyze the levels of cellular apoptosis. The results were calculated using 
A

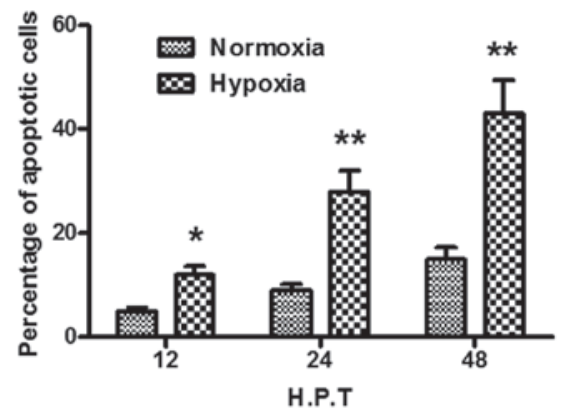

C

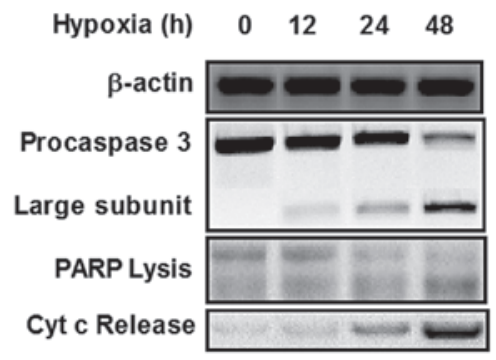

$\mathbf{E}$

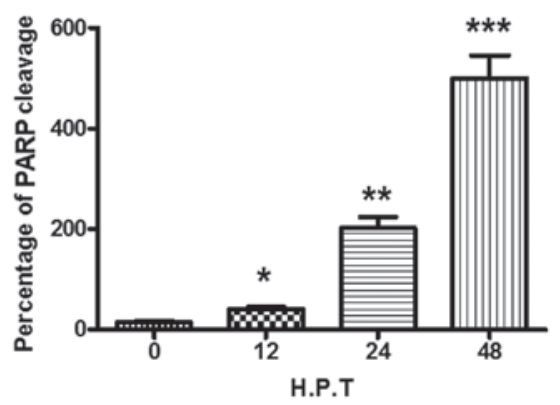

B

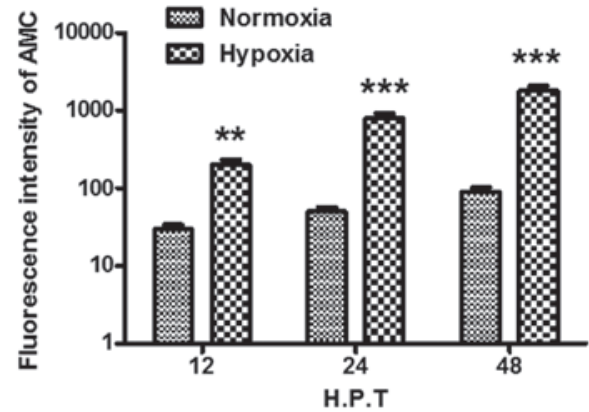

D

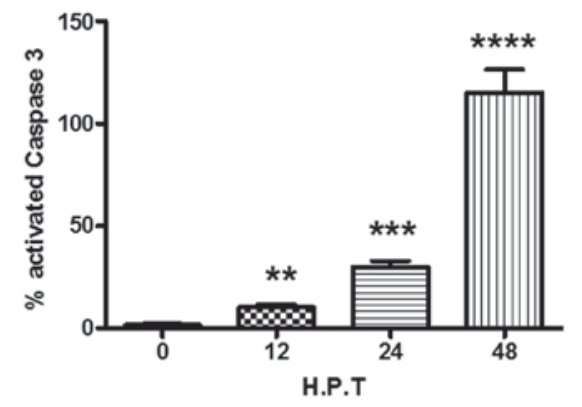

$\mathbf{F}$

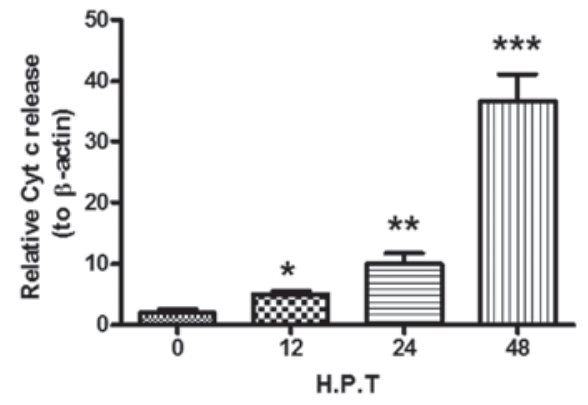

Figure 1. Hypoxia induces the apoptosis of PC12 cells. The PC12 cells were exposed to hypoxic or normoxic conditions for 12,24 or 48 h. (A) $4 \times 10^{5}$ cells were stained with Annexin V-fluorescein isothiocyanate and propidium iodide and detected using a FACS can flow cytometer to analyze cellular apoptosis. Results are expressed as the percentage of apoptotic cells to total cells. (B) Caspase 3 activity in the PC12 cells. Cell lysates were added to assay plates containing Ac-DEVD-AMC substrate solution, and plates were incubated at $37^{\circ} \mathrm{C}$ in the dark. Relative fluorescent units were determined at $2 \mathrm{~h}$. (C) Western blot analysis of caspase 3 activation, PARP cleavage and cytochrome $c$ release in PC12 cells under hypoxic conditions. (D) Percentage of activated caspase 3 to pro-caspase 3; (E) Percentage of lyzed PARP to intact PARP; (F) Percentage of cytochrome $c$ release, relative to $\beta$-actin. All experiments were performed in triplicate and data are presented as the mean \pm standard error of the mean. ${ }^{*} \mathrm{P}<0.05,{ }^{* * *} \mathrm{P}<0.01,{ }^{* * * *} \mathrm{P}<0.001$ and ${ }^{* * * * *} \mathrm{P}<0.0001$, compared with the normoxic control. AMC, 7-amino-4-methylcoumarin; PARP, poly(ADP-ribose) polymerase; Cyt c, cytochrome $c$; H.P.T, hours post-treatment.

CellQuest $^{\mathrm{TM}}$ Pro software (Bio-Rad Laboratories, Inc.) and expressed as the percentage of apoptotic cells in the total cells. The activity of caspase 3 was examined using a Caspase 3 Activity Assay kit (Cell Signaling Technology, Inc.), according to the manufacturer's instructions, with the activity expressed as the relative fluorescence intensity of 7-amino-4-methylcoumarin (AMC), compared with the control.

Statistical analysis. Statistical analyses were performed using SPSS 16.0 software (SPSS, Inc., Chicago, IL, USA). Comparison of the mRNA and protein expression levels of HIF- $1 \alpha$ and RhoA, the percentage of apoptotic cells and the activity of caspase 3 between the two groups were analyzed using Student's $t$-test. $\mathrm{P}<0.05$ was considered to indicate a statistically significant difference.

\section{Results}

Hypoxia induces the apoptosis of PC12 cells. In the present study, flow cytometric analysis was used to measure the level of apoptosis of cells of the PC12 rat pheochromocytoma cell line, induced by hypoxia. When the cells were exposed to hypoxia for $12 \mathrm{~h}, 24 \mathrm{~h}$ or $48 \mathrm{~h}$, significantly more PC12 cells underwent apoptosis, compared with the cells under normoxic conditions ( $\mathrm{P}<0.05$ or $\mathrm{P}<0.01$; Fig. $1 \mathrm{~A})$. Procaspase 3 undergoes cleavage and activation in apoptosis (29), and hypoxia 
A

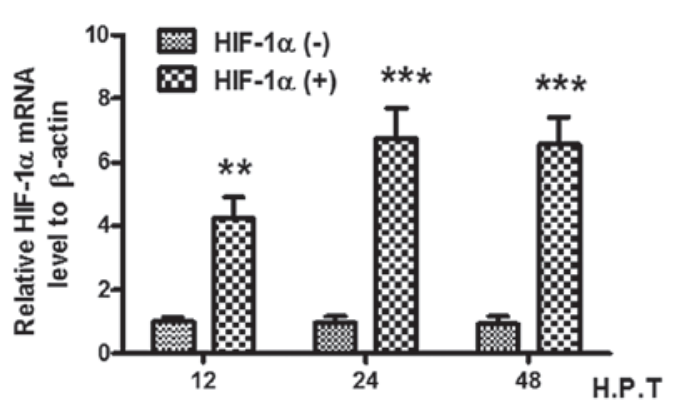

C

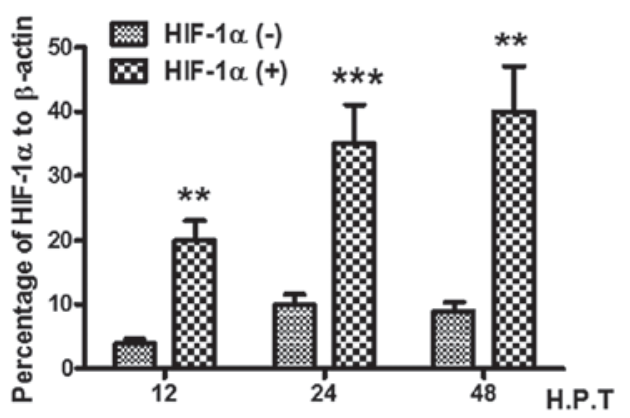

$\mathbf{E}$

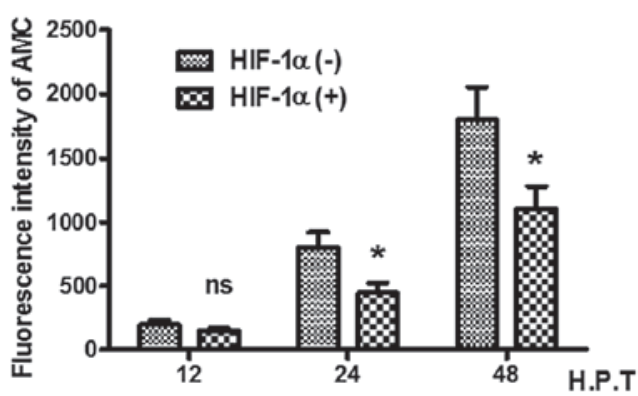

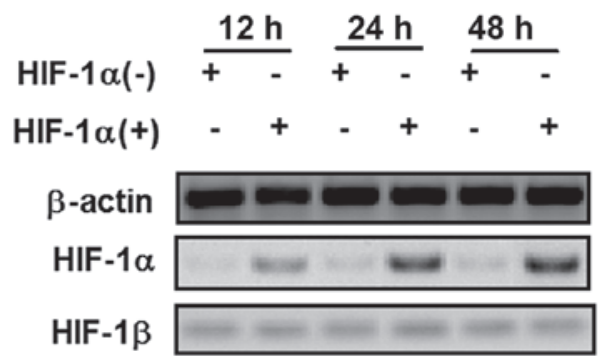

D

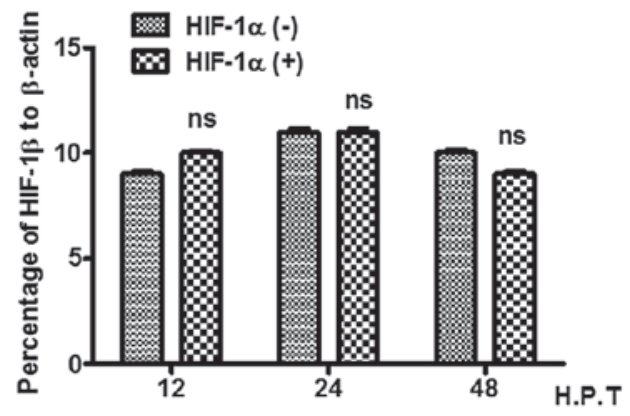

Figure 2. HIF-1 $\alpha$ antagonizes the hypoxia-induced apoptosis of PC12 cells. The PC12 cells were transfected with a pcDNA3.1-HIF-1 $\alpha$ or control pcDNA3.1-CAT-plasmid for 12, 24 and 48 h. (A) Relative mRNA expression of HIF-1 $\alpha$ in HIF-1 $\alpha$-overexpressed PC12 cells. (B) Western blot analysis of HIF-1 $\alpha$ and HIF-1 $1 \beta$ in HIF-1 $\alpha$-overexpressed PC12 cells. Relative expression of (C) HIF-1 $\alpha$ and (D) HIF-1 $\beta$ as percentage of $\beta$-actin. (E) Caspase 3 activity, determined by Acetyl-DEVD-AMC substrate lyzation analysis, in HIF-1a-overexpressed PC12 cells under hypoxic conditions. (F) Apoptosis in HIF-1a-overexpressed PC12 cells under hypoxic conditions, revealed using a FACScan flow cytometer. All experiments were performed in triplicate and data are presented as the mean \pm standard error of the mean. ${ }^{*} \mathrm{P}<0.05$ and ${ }^{* *} \mathrm{P}<0.01$, compared with the HIF-1 $\alpha(-)$ group, ns, no significance; HIF, hypoxia-inducible factor; AMC, 7-amido-4-methylcoumari; H.P.T, hours post-treatment.

treatment also induced higher levels of caspase 3 activity in the present study, which was evaluated by measuring the fluorescence intensity of AMC, compared with the control $\mathrm{PC} 12$ cells $(\mathrm{P}<0.01$ or $\mathrm{P}<0.001 ;$ Fig. 1B). The cleavage of procaspase 3 in the $\mathrm{PC} 12$ cells following hypoxia treatment was also examined (Fig. 1C). As shown in Fig. 1D, a higher level of procaspase 3 was cleaved into its 17 and $12 \mathrm{kDa}$ subunits in the soluble protein in the PC12 cells, compared with the control $(\mathrm{P}<0.01)$. To further determine whether PC12 cell death by hypoxia was mediated by caspase- 3 activation, the cleavage of poly(ADP-ribose) polymerase (PARP) by activated caspase 3 was examined. The results demonstrated that, following exposure to hypoxia for $48 \mathrm{~h}, \mathrm{PARP}$ cleavage was significantly promoted $(\mathrm{P}<0.05$; Fig. $1 \mathrm{C}$ and $\mathrm{E})$. The present study also determined the release of cytochrome $c$, which is translocated between the mitochondria and the cytosol where it assists in activating caspases. As shown in Fig. 1C and F, hypoxia also significantly enhanced the release of cytochrome $c(\mathrm{P}<0.05)$.

HIF-1a antagonizes hypoxia-induced apoptosis of PC12 cells. To determine whether HIF-1 $\alpha$ alters hypoxia-induced apoptosis in PC12 cells, an plasmid overexpressing the HIF-1 $\alpha$ gene was transfected into PC12 cells, and the mRNA and protein levels of HIF- $1 \alpha$ and HIF-1 $\beta$ were evaluated using RT-qPCR and western blot analysis. As shown in Fig. 2A, the expression of HIF-1 $\alpha$ was over four times higher in the HIF-1 $\alpha$-overexpressing plasmid-transfected cells $(\mathrm{P}<0.01)$, 
A

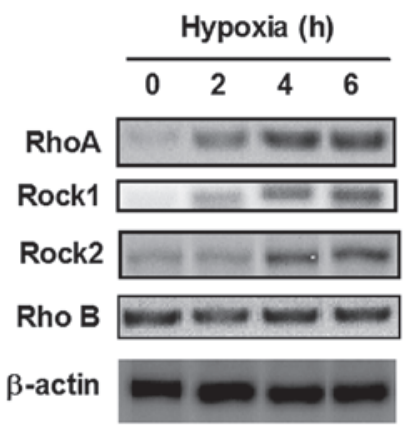

C

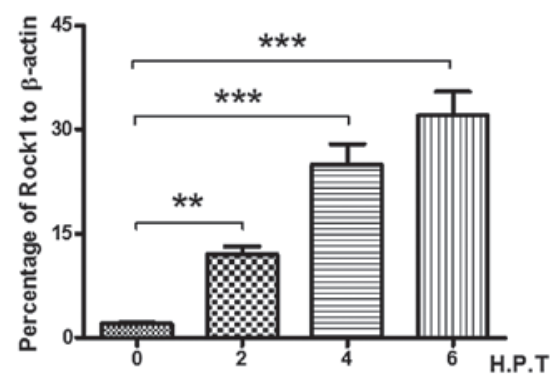

B

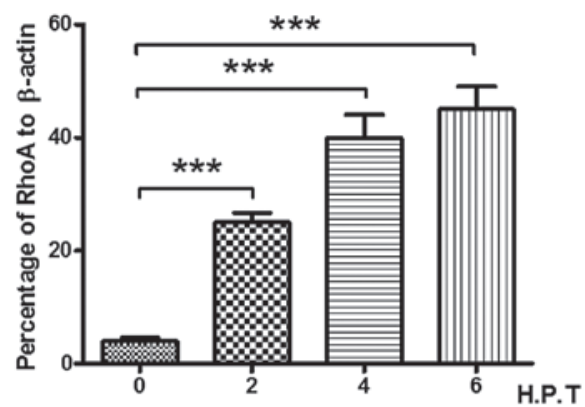

D

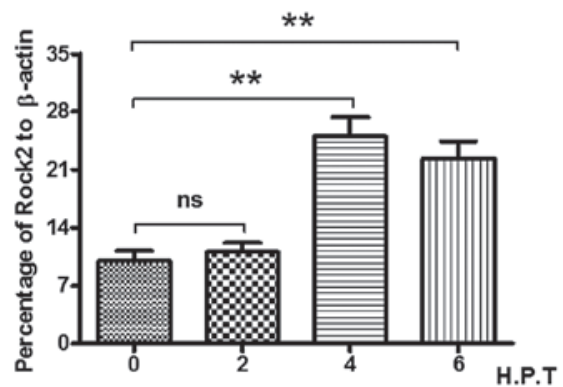

$\mathbf{E}$

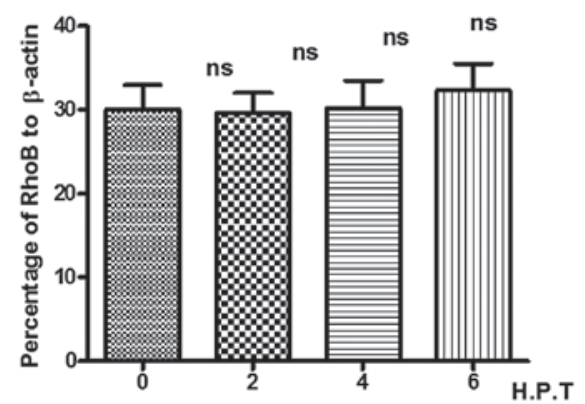

Figure 3. Hypoxia induces RhoA in PC12 cells. The PC12 cells were exposed to hypoxic conditions for $0,2,4,6$ and $8 \mathrm{~h}$ and were analyzed for the expression of RhoA, Rock 1 and Rock 2. (A) Western blot analysis of the expression levels of RhoA, Rock1, Rock2 and RhoB in hypoxia-treated PC12 cells. Percentage of (B) RhoA, (C) Rock1, (D) Rock2 or (E) RhoB to $\beta$-actin in the hypoxia-treated PC12 cells. All experiments were performed in triplicate and data are presented as the mean \pm standard error of the mean. ${ }^{* *} \mathrm{P}<0.01$ and ${ }^{* * * *} \mathrm{P}<0.001$. Rho, Ras homolog gene family, member A; Rock, Rho-associated kinase; ns, no significance; H.P.T, hours post-treatment.

compared with the control plasmid-transfeted cells. The protein level of HIF was also increased in the HIF-1 $\alpha$ overexpression-plasmid-transfected cells $(\mathrm{P}<0.01$ or $\mathrm{P}<0.001$; Fig. 2B and $\mathrm{C}$ ), whereas the expression of HIF-1 $\beta$ was not regulated by HIF-1 $\alpha$ overexpression (Fig. 2B and D). Subsequently, to determine whether HIF-1 $\alpha$ alters hypoxia-induced apoptosis, the present study re-evaluated the activity of caspase 3 by measuring the AMC fluorescence intensity of the PC12 cells with or without HIF-1 $\alpha$ transfection. As shown in Fig. 2E, HIF-1 $\alpha$ overexpression inhibited caspase 3 activity from $24 \mathrm{~h}$ post-transfection, and less AMC fluorescence intensity was observed in the HIF-1 $\alpha$-overexpressed $\mathrm{PC} 12$ cells $(\mathrm{P}<0.05)$ 24 or $48 \mathrm{~h}$ post-transfection). In addition, flow cytometric analysis revealed that the overexpression of HIF- $1 \alpha$ inhibited the hypoxia-induced apoptosis of the PC12 cells $(\mathrm{P}<0.05) 24$ or $48 \mathrm{~h}$ post-transfection; Fig. 2F). Taken together, these findings indicated that the overexpression of HIF-1 $\alpha$ attenuated hypoxia-induced $\mathrm{PC} 12$ cell apoptosis.
Hypoxia induces RhoA in PC12 cells. RhoA has been reported to be activated by chronic hypoxia in the lungs $(30,31)$, as two of the key downstream effectors of RhoA, Rock 1 and Rock 2, have been confirmed to be involved in the lung response to hypoxia (32). In present study, to determine possible role of RhoA, Rock 1, Rock 2 and RhoB in hypoxia-induced PC12 cell apoptosis, the present study examined the expression levels of the three molecules in PC12 cells. As shown in Fig. 3A and B, the expression of RhoA was markedly upregulated by $>10$-fold, between 2 and $6 \mathrm{~h}$ post-hypoxia $(\mathrm{P}<0.001)$. The expression of Rock 1 was also significantly upregulated in the PC12 cells from $2 \mathrm{~h}$ post-hypoxia exposure, with a $\sim 30$-fold elevation in the expression of Rock 1 following hypoxia stimulation $(\mathrm{P}<0.01$ or $\mathrm{P}<0.001$; Fig $3 \mathrm{C})$. Notably, the expression levels of Rock 2 appeared to change minimally on hypoxia stimulation, and began to increase $4 \mathrm{~h}$ post-hypoxia exposure, with an elevation of only three-fold (Fig. 3D). RhoB, an inhibitor of Rho activity, was unresponsive to 
A

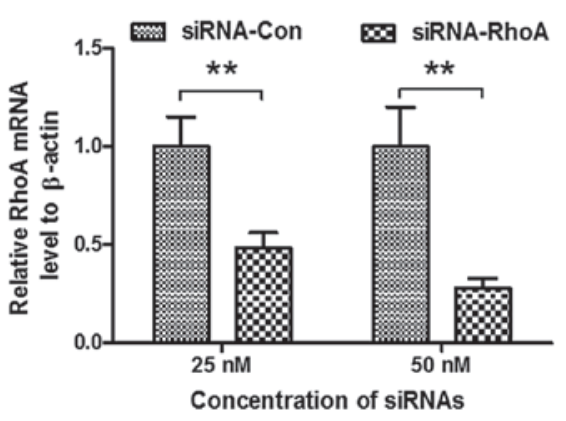

C

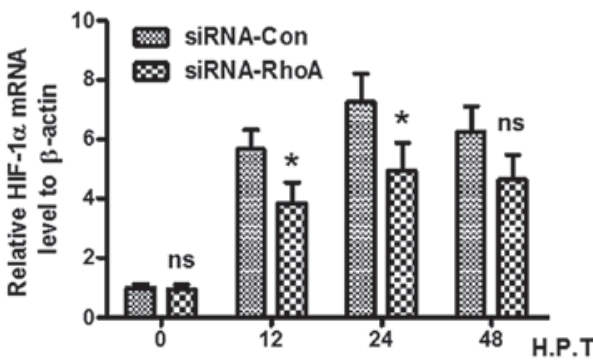

D

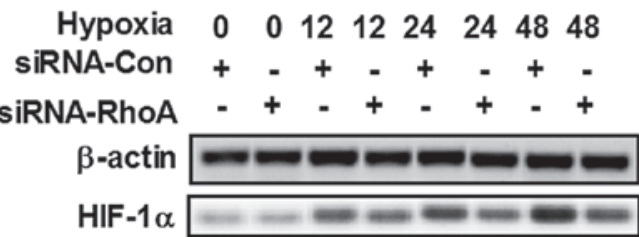

F

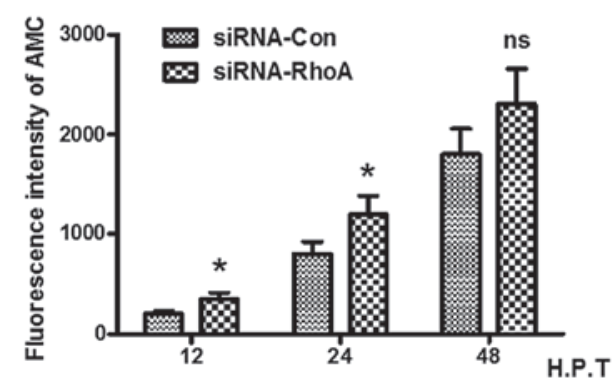

B
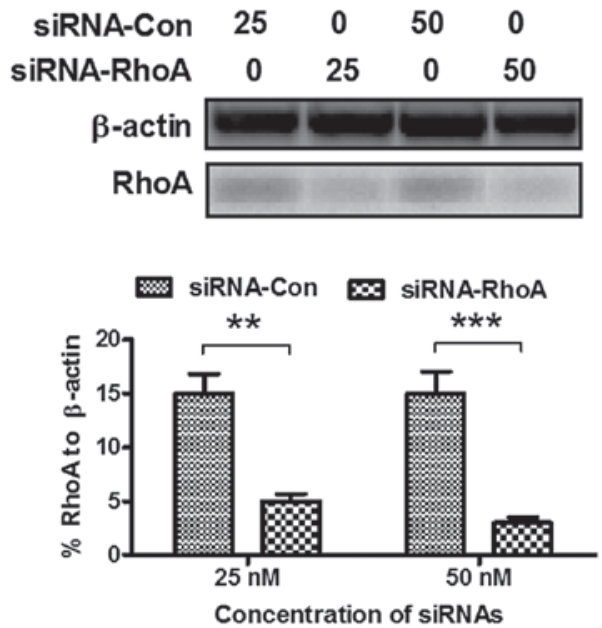

E

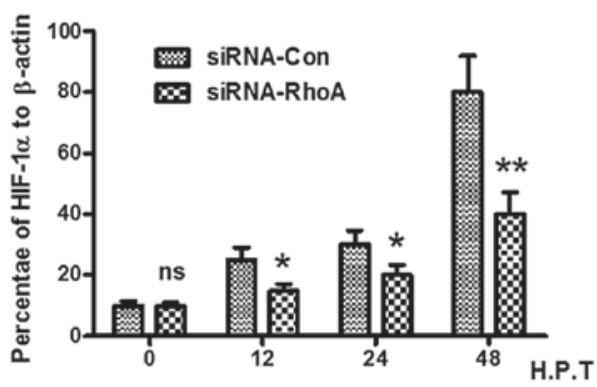

G

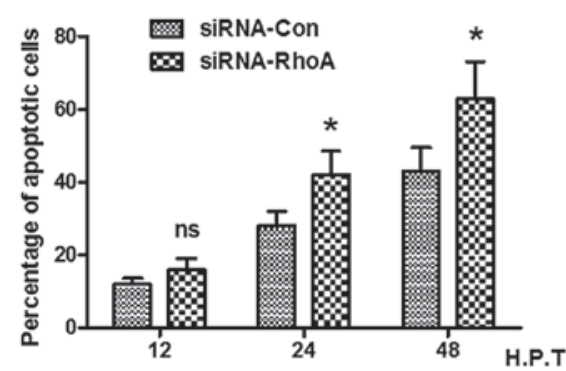

Figure 4. Hypoxia-induced HIF-1 $\alpha$ is RhoA-dependent. (A) Relative mRNA expression levels of RhoA in PC12 cells transfected with RhoA-targeted siRNA; results are expressed relative to $\beta$-actin. (B) Western blot analysis of RhoA in PC12 cells following transfection with RhoA-targeted siRNA. (C) Relative mRNA expression of HIF-1 $\alpha$ in PC12 cells with RhoA knockdown, results are expressed relative to $\beta$-actin. (D) Western blot analysis of the induction of HIF-1 $\alpha$ by hypoxia in PC12 cells following RhoA knockdown (transfection with $50 \mathrm{nM}$ siRNA-RhoA or siRNA-Con for 12, 24 and 48 h). (E) Relative expression of HIF- $1 \alpha$ as percentage of $\beta$-actin. (F) Caspase 3 activity determined using Acetyl-DEVD-AMC substrate lyzation analysis, in PC12 cells under hypoxic conditions following RhoA knockdown. (G) Apoptotic cells induced by hypoxia following RhoA knockdown. All experiments were performed in triplicate and data are presented as the mean \pm standard error of the mean. ${ }^{*} \mathrm{P}<0.05,{ }^{* *} \mathrm{P}<0.01$ and ${ }^{* * *} \mathrm{P}<0.001$, compared with the control. HIF, hypoxia-inducible factor; RhoA, Ras homolog gene family, member A; ROCK, Rho-associated kinase; siRNA, small interfering RNA; AMC, 7-amido-4-methylcoumari; Con, control; H.P.T, hours post-treatment; ns, no significance.

hypoxia stimulation, with no significant change between 2 and $6 \mathrm{~h}$ post-hypoxia exposure (Fig.3E). Therefore, RhoA signaling was significantly promoted by hypoxia in the PC12 cells, and RhoA became the focus of subsequent experiments to investigate levels of expression and to investigate the molecular mechanisms used by the Rho proteins to regulate hypoxic responses.

Hypoxia-induced HIF-1 $\alpha$ is RhoA-dependent. The present study used RhoA specific siRNA to investigate the effect 
of RhoA on the promotion of HIF- $1 \alpha$. First, the mRNA and protein levels of RhoA were measured using RT-qPCR and western blotting following the transfection of siRNAs specific for RhoA ( 25 or $50 \mathrm{nM}$ ) into the PC12 cells. It was observed that 25 or $50 \mathrm{nM}$ anti-RhoA siRNA significantly inhibited the mRNA and protein expression levels of RhoA (Fig. 4A and B). It was also demonstrated that the mRNA expression of HIF-1 $\alpha$ under hypoxia treatment also reduced following anti-RhoA siRNA transfection in the PC12 cells between 12 and $24 \mathrm{~h}$, which suggested that hypoxia-induced HIF-1 $\alpha$ was RhoA-dependent $(\mathrm{P}<0.05)$. The present study also examined whether transfection with anti-RhoA siRNA regulated the protein expression of HIF-1 $\alpha$. As shown in Fig. 4D and E, compared with the siRNA control-transfected PC12 cells, siRNA targeting RhoA significantly inhibited hypoxia-induced the protein expression of HIF-1 $\alpha$ at $12,24 \mathrm{~h}(\mathrm{P}<0.05)$ and $48 \mathrm{~h}(\mathrm{P}<0.01)$ post-hypoxia.

RhoA knockdown abrogates the antagonism of HIF-la in hypoxia-induced apoptosis of PC12 cells. As shown in Fig. 2, HIF-1 $\alpha$ was observed to antagonize hypoxia-induced apoptosis of the PC12 cells, whereas the overexpression of HIF-1 $\alpha$ in the PC12 cells was inhibited by RhoA knockdown by siRNA transfection. The present study investigated whether RhoA knockdown can reverse this change. Following co-transfection with anti-RhoA siRNA and the pcDNA-HIF-1 $\alpha$ plasmid, the PC12 cells were treated with hypoxia for 12, 24 and $48 \mathrm{~h}$. The fluorescence intensity of AMC revealed that the transfection with RhoA siRNA significantly improved hypoxia-induced caspase 3 activity with HIF-1 $\alpha$ treatment (Fig. 4E). Flow cytometric analysis also indicated that more apoptotic cells were formed in the RhoA siRNA transfected PC12 cells, compared with the control siRNA group (Fig. 4F). In conclusion, knockdown of RhoA in the PC12 cells abrogated the antagonism of HIF-1 $\alpha$ to hypoxia-induced apoptosis.

\section{Discussion}

Hypoxic conditions regulate several metabolic enzymes and transcription factors, which are involved in cancer, ischemia and pulmonary diseases (33). HIF-1 is a transcription factor induced by hypoxia, which possesses two subunits, HIF-1 $\alpha$ and HIF-1 $\beta$ (34). Several studies have demonstrated that reactive oxygen species (ROS) generation is necessary for the transcriptional response induced by hypoxia $(35,36)$. The addition of diphenylene iodonium, an inhibitor of ROS, or the use of cells depleted in mitochondria can eradicate the hypoxic induction of HIF-1 $\alpha$, erythropoietin, glycolytic enzymes and vascular endothelial growth factor (37). Analysis of the events upstream of HIF-1 $\alpha$ has suggested the importance of the generation of ROS in hypoxia via mitochondria as a sensor of oxygen levels, and that ROS may be involved in stabilizing HIF-1 $\alpha(36,38)$.

RhoA belongs to the Rho small GTPase family, within the Ras-like protein superfamily, which also includes the Ras, Rab, Arf and Ran families (39). Rho molecules are highly conserved between eukaryotes and mammals (40). Following activation, Rho GTPases trigger a signaling cascade to direct a variety of cellular responses (41-43). Rho GTPases have been reported to contribute to the majority of steps of cancer initiation and progression, including unlimited proliferation potential and evasion from apoptosis, and several Rho GTPases are upregulated in certain types of human tumor, including RhoA, RhoC, Rac1 $(44,45)$. The upregulated Rho GTPases exert their pro-oncogenic effects via the stimulation of cell cycle progression and regulation of gene transcription (46). Certain Rho GTPases are considered to be able to regulate the release of pro-angiogenic factors to promote neovascularisation (47). Interacting with the plasma membrane, RhoA modulates downstream signaling pathways to regulate cell cycle and survival $(48,49)$. In addition, RhoA is essential in cancer cell migration and invasion (50-52). RhoA has been suggested to be involved in several anti-apoptotic pathways in the suppression of apoptosis. The expression of RhoA promotes activation of extracellular signal-regulated kinase (ERK) and facilitates glomerular epithelial cells survival (53). RhoA also upregulates the expression of anti-apoptotic Bcl-2 in T cells (54), vascular smooth muscle cells (55) and osteosarcoma cells (56). In addition, Rho inhibition induces p53 in human endothelial cells (57).

Apoptosis during CNS/PNS damage is reversible and is regarded as a major target of therapeutic interventions $(15,16)$. In the present study, hypoxia was demonstrated to induce apoptosis of PC12 cells. Hypoxia had a significant effect on PC12 cell apoptosis (Fig. 1), including caspase 3 activation and cytochrome $c$ release. Secondly, transfection of an expression plasmid into PC12 cells revealed that the overexpression of HIF-1 $\alpha$ inhibited hypoxia-induced PC12 cell apoptosis (Fig. 2). To improve understanding of the mechanisms involved in the upregulation of RhoA, the present study investigated its expression in hypoxia-induced PC12 cells. The promotion of HIF-1 $\alpha$ and RhoA, which is reported to be involved in hypoxia adaptation, was observed in the neuroblastoma $\mathrm{PC} 12$ cells following exposure to hypoxia (Fig. 3). By inducing the overexpression and inhibition of RhoA, the present study manipulated the level of HIF-1 $\alpha$ in the PC12 cells, and revealed that hypoxia induced RhoA upregulation and cell apoptosis. The results further confirmed the protective role of HIF-1 $\alpha$ and RhoA in hypoxia-induced $\mathrm{PC} 12$ cell apoptosis, and that the upregulation of RhoA by hypoxia was HIF-1 $\alpha$-dependent (Fig. 4).

In conclusion, the present study demonstrated that HIF-1 $\alpha$ upregulation protected PC12 neuroblastoma cells from hypoxia-induced apoptosis in a RhoA-dependent manner, and the promotion of HIF-1 $\alpha$ and RhoA may be a valuable strategy for therapeutic intervention for hypoxic-ischemic damage to the CNS/PNS.

\section{Acknowledgements}

This study was supported by a postdoctoral grant (grant no. QL2012035) from Qilu Hospital of Shandong University (Jinan, China).

\section{References}

1. Wishart TM, Parson SH and Gillingwater TH: Synaptic vulnerability in neurodegenerative disease. J Neuropathol Exp Neurol 65: 733-739, 2006

2. Whiteley W, Tseng MC and Sandercock P: Blood biomarkers in the diagnosis of ischemic stroke: A systematic review. Stroke 39: 2902-2909, 2008.

3. Kam PC, Kavanagh R and Yoong FF: The arterial tourniquet: Pathophysiological consequences and anaesthetic implications. Anaesthesia 56: 534-545, 2001 
4. McEwen JA: Complications of and improvements in pneumatic tourniquets used in surgery. Med Instrum 15: 253-257, 1981.

5. Rorabeck CH: Tourniquet-induced nerve ischemia: An experimental investigation. J Trauma 20: 280-286, 1980.

6. Bickler PE and Donohoe PH: Adaptive responses of vertebrate neurons to hypoxia. J Exp Biol 205: 3579-3586, 2002.

7. Nishimura M: Factors influencing an increase in spontaneous transmitter release by hypoxia at the mouse neuromuscular junction. J Physiol 372: 303-313, 1986.

8. Bukharaeva EA, Salakhutdinov RI, Vyskocil F and Nikolsky EE: Spontaneous quantal and non-quantal release of acetylcholine at mouse endplate during onset of hypoxia. Physiol Res 54: 251-255, 2005.

9. David G, Nguyen K and Barrett EF: Early vulnerability to ischemia/reperfusion injury in motor terminals innervating fast muscles of SOD1-G93A mice. Exp Neurol 204: 411-420, 2007.

10. Hatzipantelis KP, Natsis K and Albani M: Effect of acute limb ischaemia on neuromuscular function in rats. Eur J Surg 167: 831-838, 2001

11. Northington FJ, Ferriero DM, Flock DL and Martin LJ: Delayed neurodegeneration in neonatal rat thalamus after hypoxia-ischemia is apoptosis. J Neurosci 21: 1931-1938, 2001.

12. Graham SH and Chen J: Programmed cell death in cerebral ischemia. J Cereb Blood Flow Metab 21: 99-109, 2001.

13. Linnik MD, Zobrist RH and Hatfield MD: Evidence supporting a role for programmed cell death in focal cerebral ischemia in rats. Stroke 24: 2002-2008, discussion 2008-2009, 1993.

14. Ferrer I and Planas AM: Signaling of cell death and cell survival following focal cerebral ischemia: Life and death struggle in the penumbra. J Neuropathol Exp Neurol 62: 329-339, 2003.

15. Kato $\mathrm{H}$ and Kogure $\mathrm{K}$ : Biochemical and molecular characteristics of the brain with developing cerebral infarction. Cell Mol Neurobiol 19: 93-108, 1999.

16. Newcomb JD, Ajmo CJ,Sanberg CD, Sanberg PR,Pennypacker KR and Willing AE: Timing of cord blood treatment after experimental stroke determines therapeutic efficacy. Cell Transplant 15 : 213-223, 2006.

17. Cummins EP and Taylor CT: Hypoxia-responsive transcription factors. Pflugers Arch 450: 363-371, 2005.

18. Licausi F, Weits DA, Pant BD, Scheible WR, Geigenberger P and van Dongen JT: Hypoxia responsive gene expression is mediated by various subsets of transcription factors and miRNAs that are determined by the actual oxygen availability. New Phytol 190 : 442-456, 2011.

19. Semenza GL: Targeting HIF-1 for cancer therapy. Nat Rev Cancer 3: 721-732, 2003.

20. Wang GL, Jiang BH, Rue EA and Semenza GL: Hypoxia-inducible factor 1 is a basic-helix-loop-helix-PAS heterodimer regulated by cellular O2 tension. Proc Natl Acad Sci USA 92: 5510-5514, 1995.

21. Pouyssegur J, Dayan F and Mazure NM: Hypoxia signalling in cancer and approaches to enforce tumour regression. Nature 441: 437-443, 2006 .

22. Kaelin WJ and Ratcliffe PJ: Oxygen sensing by metazoans: The central role of the HIF hydroxylase pathway. Mol Cell 30: 393-402, 2008

23. Piret JP, Mottet D, Raes M and Michiels C: Is HIF-1alpha a pro- or an anti-apoptotic protein? Biochem Pharmacol 64: 889-892, 2002.

24. Akakura N, Kobayashi M, Horiuchi I, Suzuki A, Wang J, Chen J, Niizeki H, Kawamura KI, Hosokawa M and Asaka M: Constitutive expression of hypoxia-inducible factor-1alpha renders pancreatic cancer cells resistant to apoptosis induced by hypoxia and nutrient deprivation. Cancer Res 61: 6548-6554, 2001.

25. Zhang B, Yin CP, Zhao Q and Yue SW: Upregulation of hif-1 $\alpha$ by hypoxia protect neuroblastoma cells from apoptosis by promoting survivin expression. Asian Pac J Cancer Prev 15: 8251-8257, 2014

26. Chen D, Li M, Luo J and Gu W: Direct interactions between HIF-1 alpha and Mdm2 modulate p53 function. J Biol Chem 278: $13595-13598,2003$.

27. Kothari S, Cizeau J, McMillan-Ward E, Israels SJ, Bailes M, Ens K, Kirshenbaum LA and Gibson SB: BNIP3 plays a role in hypoxic cell death in human epithelial cells that is inhibited by growth factors EGF and IGF. Oncogene 22: 4734-4744, 2003

28. Livak KJ and Schmittgen TD: Analysis of relative gene expression data using real-time quantitative PCR and the 2 (-Delta Delta C(T)) Method. Methods 25: 402-408, 2001

29. Bailly K, Ridley AJ, Hall SM and Haworth SG: RhoA activation by hypoxia in pulmonary arterial smooth muscle cells is age and site specific. Circ Res 94: 1383-1391, 2004.

30. Nicholson DW and Thornberry NA: Apoptosis. Life and death decisions. Science 299: 214-215, 2003.
31. Dada LA, Novoa E, Lecuona E, Sun H and Sznajder JI: Role of the small GTPase RhoA in the hypoxia-induced decrease of plasma membrane Na, K-ATPase in A549 cells. J Cell Sci 120: 2214-2222, 2007

32. Desbuards N, Antier D, Rochefort GY, Apfeldorfer CS, Schenck E, Hanton G and Hyvelin JM: Dexfenfluramine discontinuous treatment does not worsen hypoxia-induced pulmonary vascular remodeling but activates RhoA/ROCK pathway: Consequences on pulmonary hypertension. Eur J Pharmacol 602: 355-363, 2009.

33. Semenza GL: HIF-1 and human disease: One highly involved factor. Genes Dev 14: 1983-1991, 2000.

34. Wang GL and Semenza GL: Purification and characterization of hypoxia-inducible factor 1. J Biol Chem 270: 1230-1237, 1995.

35. Li C and Jackson RM: Reactive species mechanisms of cellular hypoxia-reoxygenation injury. Am J Physiol Cell Physiol 282: C227-C241, 2002.

36. Chandel NS and Schumacker PT: Cellular oxygen sensing by mitochondria: Old questions, new insight. J Appl Physiol (1985) 88: $1880-1889,2000$

37. Chandel NS, Maltepe E, Goldwasser E, Mathieu CE, Simon MC and Schumacker PT: Mitochondrial reactive oxygen species trigger hypoxia-induced transcription. Proc Natl Acad Sci USA 95: 11715-11720, 1998.

38. Pearlstein DP, Ali MH, Mungai PT, Hynes KL, Gewertz BL and Schumacker PT: Role of mitochondrial oxidant generation in endothelial cell responses to hypoxia. Arterioscler Thromb Vasc Biol 22: 566-573, 2002.

39. Vega FM and Ridley AJ: Rho GTPases in cancer cell biology. FEBS Lett 582: 2093-2101, 2008.

40. Boureux A, Vignal E, Faure S and Fort P: Evolution of the Rho family of ras-like GTPases in eukaryotes. Mol Biol Evol 24: 203-216, 2007.

41. Jaffe AB and Hall A: Rho GTPases: Biochemistry and biology. Annu Rev Cell Dev Biol 21: 247-269, 2005.

42. Bishop AL and Hall A: Rho GTPases and their effector proteins. Biochem J 348 Pt 2: 241-255, 2000.

43. Wilkins A and Insall RH: Small GTPases in Dictyostelium: Lessons from a social amoeba. Trends Genet 17: 41-48, 2001.

44. Gomez del Pulgar T, Benitah SA, Valerón PF, Espina C and Lacal JC: Rho GTPase expression in tumourigenesis: Evidence for a significant link. Bioessays 27: 602-613, 2005.

45. Gouw LG, Reading NS, Jenson SD, Lim MS and Elenitoba-Johnson KS: Expression of the Rho-family GTPase gene RHOF in lymphocyte subsets and malignant lymphomas. Br J Haematol 129: 531-533, 2005.

46. Benitah SA, Valerón PF, van Aelst L, Marshall CJ and Lacal JC: Rho GTPases in human cancer: An unresolved link to upstream and downstream transcriptional regulation. Biochim Biophys Acta 1705: 121-132, 2004

47. Merajver SD and Usmani SZ: Multifaceted role of Rho proteins in angiogenesis. J Mammary Gland Biol Neoplasia 10: 291-298, 2005.

48. Wong WW, Dimitroulakos J, Minden MD and Penn LZ: HMG-CoA reductase inhibitors and the malignant cell: The statin family of drugs as triggers of tumor-specific apoptosis. Leukemia 16: 508-519, 2002

49. Graaf MR, Richel DJ, van Noorden CJ and Guchelaar HJ: Effects of statins and farnesyltransferase inhibitors on the development and progression of cancer. Cancer Treat Rev 30: 609-641, 2004.

50. Denoyelle C, Vasse M, Korner M, Mishal Z, Ganné F, Vannier JP, Soria J and Soria C: Cerivastatin, an inhibitor of HMG-CoA reductase, inhibits the signaling pathways involved in the invasiveness and metastatic properties of highly invasive breast cancer cell lines: An in vitro study. Carcinogenesis 22: 1139-1148, 2001

51. Sawada K, Morishige K, Tahara M, Kawagishi R, Ikebuchi Y, Tasaka K and Murata Y: Alendronate inhibits lysophosphatidic acid-induced migration of human ovarian cancer cells by attenuating the activation of rho. Cancer Res 62: 6015-6020, 2002

52. Kusama T, Mukai M, Tatsuta M, Nakamura $H$ and Inoue $M$ : Inhibition of transendothelial migration and invasion of human breast cancer cells by preventing geranylgeranylation of Rho. Int J Oncol 29: 217-223, 2006.

53. Bijian K, Takano T, Papillon J, Le Berre L, Michaud JL, Kennedy CR and Cybulsky AV: Actin cytoskeleton regulates extracellular matrix-dependent survival signals in glomerular epithelial cells. Am J Physiol Renal Physiol 289: F1313-F1323, 2005. 
54. Gómez J, Martínez C, Giry M, García A and Rebollo A: Rho prevents apoptosis through Bcl-2 expression: Implications for interleukin-2 receptor signal transduction. Eur J Immunol 27: 2793-2799, 1997.

55. Blanco-Colio LM, Villa A, Ortego M, Hernández-Presa MA, Pascual A, Plaza JJ and Egido J: 3-Hydroxy-3-methyl-glutaryl coenzyme A reductase inhibitors, atorvastatin and simvastatin, induce apoptosis of vascular smooth muscle cells by downregulation of $\mathrm{Bcl}-2$ expression and Rho A prenylation. Atherosclerosis 161: 17-26, 2002.
56. Fromigué O, Haÿ E, Modrowski D, Bouvet S, Jacquel A, Auberger P and Marie PJ: RhoA GTPase inactivation by statins induces osteosarcoma cell apoptosis by inhibiting p42/p44-MAPKs-Bcl-2 signaling independently of BMP-2 and cell differentiation. Cell Death Differ 13: 1845-1856, 2006.

57. Li X, Liu L, Tupper JC, Bannerman DD, Winn RK, Sebti SM, Hamilton AD and Harlan JM: Inhibition of protein geranylgeranylation and RhoA/RhoA kinase pathway induces apoptosis in human endothelial cells. J Biol Chem 277: 15309-15316, 2002. 